\title{
ÉTICA Y SOCIEDAD. A. W. H. ADKINS Y LOS VALORES MORALES EN HOMERO
}

\author{
Matías Leiva R. \\ Universidad Andrés Bello. Chile
}

Resumen: La ética homérica ha sido objeto de estudio de diversos académicos y filósofos. Sin embargo, el interesante análisis llevado a cabo por A.W.H. Adkins lo sitúa como uno de los referentes en la materia. Siguiendo su rigurosa investigación filológica, en este artículo intentaremos demostrar que la 'ética homérica' no sobrepasa los límites de su propio contexto y no constituye un sistema ético propiamente tal, sino más bien debe entenderse como un código de conducta que nace de las acciones de los hombres y que tiene por objetivo el funcionamiento de una sociedad orientada a la guerra y la competencia.

Palabras claves: Ética, moralidad, honor, utilidad, actos humanos.

\section{ETHICS AND SOCIETY.}

\section{A.W.H. ADKINS AND THE MORAL VALUES IN HOMER}

\begin{abstract}
Homeric Ethics has been studied by several academics and philosophers. However, the interesting analysis made by A.W.H. Adkins places him as a key author on the subject. In this article, following Adkins' rigorous philological investigation, we will attempt to demonstrate that the "Homeric Ethics" does not surpass the limits of its own context and that it does not constitute, properly, an ethical system, but rather must be understood as a code of conduct that is born from the actions of men and that aims to produce a functional society oriented towards war and competition.
\end{abstract}

Key words: Ethics, morality, honor, utility, human actions.

Recibido: 10.08.2017 - Aceptado: 2.10.2017

Correspondencia: Matías Leiva Rodríguez.

Email: matiasleiva@gmail.com

Lic. Filosofía y Lic. Educación en P. Universidad Católica de Valparaíso.

MA in Classics, Nottingham University.

Prof. De Filosofía en Univ. Andrés Bello. Coordinador de Ética DUOC, U.C. 


\section{Introducción}

ntes de comenzar resulta necesario hacer algunas
aclaraciones de carácter metodológico. Si bien el
tratamiento que hace Adkins de los valores morales en la Grecia antigua hunde sus raíces en las ideas de sus grandes maestros, éste se caracteriza por su singularidad y desarrollo. El añadido filológico y filosófico que imprime en sus reflexiones lo sitúa como el gran referente de las reflexiones morales de Grecia en el siglo XX, particularmente su área predilecta, a saber, el mundo homérico. Para analizar su pensamiento, nos referiremos fundamentalmente a dos de sus obras. La primera es su libro "Moral Values and Political Behaviour in Ancient Greece" publicado en 1972, en el que hace un recorrido histórico, analizando el sentido social de los valores morales griegos en distintos momentos. El segundo texto es póstumo: publicado en 1997, consiste en un capítulo de un volumen de varios autores que lleva por título "A New Companion to Homer" de la editorial Brill, donde Adkins aporta con un ensayo llamado simplemente "Homeric Ethics", que constituye un resumen de todo su pensamiento en torno al tema. Tristemente no existen traducciones castellanas de ninguno de los dos textos. La bibliografía en español es escasa y sorpresivamente poco original. Hemos considerado aquí los trabajos más relevantes para nuestro estudio, entre los que destacan los ensayos del filólogo español José Lasso de la Vega, y del célebre profesor Emilio Lledó.

El primer problema al abordar un tópico como éste es la evidencia disponible. Adkins reconoce la escasa probabilidad de que los eventos narrados por la épica homérica tengan asidero histórico, reconoce incluso que es probable que una guerra, tal como la describe el poeta, nunca tuviera lugar. Sin embargo, mirando el desarrollo de los valores morales en la historia de Grecia, es posible advertir que los conceptos utilizados en la Ilíada y la Odisea fueron influyentes en épocas posteriores por lo que, aunque el poema no sea reflejo de un hecho histórico, podemos inferir que existió un pueblo que vivió y encarnó tales valores y que, a su vez, los traspasó a sus descendientes ${ }^{1}$. En este sentido, el enfoque desde el cual se deben abordar los juicios morales no es desde la mirada histórica o incluso filosófica, sino antropológica o, si se quiere, sociológica ${ }^{2}$. En

1 Adkins (1972) 10.

2 Adkins (1997) 697-98.

162 
consecuencia, la evidencia que nos servirá de material debe buscársele bajo esos parámetros, evitando poner nuestra mirada moderna como lente de observación y así tener una visión lo más prístina posible.

Homero, al evidenciar juicios y evaluaciones morales, rara vez lo hace desde la perspectiva del pobre o el mendigo, del guerrero común y sin importancia. Muy por el contrario, es cuando se refiere a los héroes que aparecen los conceptos cargados de sentido moral, en ellos tiene sentido aplicarlos. Cualquier otro personaje es relacionado a conceptos de esta índole cuando su conducta afecta en términos valóricos a un héroe o un rey. En ese sentido, es menester revisar los pasajes que explicitan estas nociones, identificando los juicios realizados y las razones que llevan a materializarlos.

\section{Agathós y kakós}

Adkins realiza un acabado e interesante análisis de la nomenclatura utilizada en la épica homérica llevar a cabo juicios morales. Reconociendo la brecha conceptual y semántica existente entre Homero y nosotros, Adkins decide, en todos sus textos, no traducir los términos usados por Homero, sino simplemente transliterarlos y ofrecer al lector la oportunidad de reconstruir una idea del campo semántico de estas voces a partir de su uso contextual. ${ }^{3}$ Ahora bien, cuando hablamos de valores no se hace alusión a abstracciones morales que nos ofrezcan conceptos nítidos y acabados. Muy por el contrario, Adkins reconoce que, para poder acceder al campo semántico de estos términos, debemos mirarlos en su uso cotidiano, considerando las evaluaciones y reacciones de la sociedad homérica tal como está expresada en la Ilíada y la Odisea ${ }^{4}$. En consecuencia, su exposición no constituye una presentación de todos los términos utilizados en los juicios morales, sino simplemente un esfuerzo por mostrar aquellos que aparecen con mayor frecuencia o que ofrezcan la oportunidad de translucir el pensar y sentir de quienes evalúan o son evaluados.

A este respecto sostiene Adkins lo siguiente:

Las palabras más enérgicas para elogiar a un individuo en el griego homérico son los adjetivos agathós y esthlós, junto con el sustantivo abstracto areté; y a su vez, las palabras más enérgicas para desacreditar son los adjetivos kakós y deilós, junto con el

3 Adkins (1972) 3-4.

4 Adkins (1972) 2. 
sustantivo abstracto kakótes. La palabra más contundente para condenar sus acciones es el adjetivo neutro aischrón; y el sustantivo abstracto elenchéie denota y denuncia la condición de un agathós que se comportó como un kakós e hizo algo aischrón ${ }^{5}$.

Respecto del primer grupo de conceptos es posible afirmar que agathós y esthlós denotan y elogian hombres que son efectivos y exitosos guerreros, ya sea formalmente en tiempos de guerra o defendiendo sus tierras en lo que, en esta sociedad, se consideran tiempos de paz. Los términos denigratorios mencionados se reservan, regularmente, para el fracaso en dicha labor ${ }^{6}$.

En la sociedad homérica, los hombres vivían en pequeñas comunidades relativamente autónomas denominadas oíkos. Cada oíkoi estaba bajo la comandancia de un jefe local referido, generalmente, como agathós. Es en el agathós donde se reúnen las virtudes morales que el grupo requería o, dicho más propiamente, el agathós es tal porque reúne las características que el oikos necesita. Estas virtudes han sido, tradicionalmente consideradas, el coraje, la fuera, la riqueza y la alta alcurnia, es decir, todo aquello que requiere un líder para defender su casa y sus súbditos. Resulta crucial que el agathós, para llevar a cabo efectivamente su tarea, deba poseerlas todas de manera conjunta. ${ }^{7}$ Es importante destacar que no es sólo la posesión de estas excelencias lo que le reporta valor al hombre; ellas deben ser utilizadas de manera eficaz y eficiente. Un agathós de buenas intenciones que falla en llevar a cabo su tarea es inservible. ${ }^{8}$ No es el coraje por sí mismo el que otorga estatus, sino

5 Adkins (1972) 12. Para esta cita y todas las posteriores, la traducción es propia desde el inglés original.

6 Lasso de la Vega (1963) 291.

7 Si bien en algunos pasajes no queda enteramente claro si el uso que le da Homero a la contradicción de esthlós y kakós es para referirse al valiente y al cobarde respectivamente o al noble y al plebeyo (Il. 2.190; Il. 14.470; Il. 4.297; Il. 11.408), en términos generales entenderemos la referencia al valiente y al cobarde. Para esta observación ver: Lasso de la Vega (1963) 292.

8 El juicio moral de la sociedad homérica no se basa en las aptitudes del héroe, sino en su deber de actuar de determinada manera, con indiferencia de si esa acción estaba dentro de sus capacidades. Para esta distinción ver: MacIntyre (1966) 17-21. 
el coraje que conduce a la victoria. Fallar es, indiferente de la intensidad del intento, reprochable y aischrón ${ }^{9}$.

Así, el agathós se constituye en el modelo de conducta para aquellos que lo rodean, son sus acciones las que constituyen el marco moral para los demás. Esta percepción de admiración y reverencia lo asemeja a los dioses; es a sus héroes a quienes recurren los hombres para su protección y salvación ${ }^{10}$. Es el mismo Príamo quien sostiene que su hijo Héctor era como un dios entre los hombres, y que parecía hijo de alguna divinidad (Il. 24.258). El agathós sirve de modelo incluso luego de fallecido, sus hazañas y su idealidad quedan vivas en la memoria: "Los hombres son, efectivamente, como las hojas de los árboles, y como ellas se suceden las generaciones. Pero a través de esa caída continua pervive el perfil que el esfuerzo heroico ha sabido marcar en la colectividad a la que pertenece"11.

En ese sentido, el agathós, una vez que recibe tal condición, lo seguirá siendo mientras ejecute con éxito su labor. Sus actos viles y bajos son perdonados por su condición. Puede mostrar intemperancia, injusticia o imprudencia, pero su estatus de modelo y la admiración que ostenta por parte de los demás lo libra de una crítica hacia su obrar ${ }^{12}$. En consecuencia, el juicio sobre un héroe, en tanto sea un líder efectivo, es siempre un juicio favorable. Para que el héroe pierda su categoría debe ser cobarde, abandonar sus tropas o faltar, de cualquier otra forma, al código de conducta propio de un agathós. Un claro ejemplo de esto son los pretendientes de Penélope. Constantemente son denotados con el término agathós, indiferente de su censurable conducta. Es el mismísimo Odiseo en el canto 23 quien reconoce, luego de haberlos matado, que dicha acción tendrá consecuencias negativas para él y su familia (Od. 23.113 ss.). Sus actos han dañando a Ítaca, pues ha privado al reino de más de cien valiosos y aristocráticos guerreros. Sin importar sus acciones ellos eran, después de todo, agathoi. Es más, los pretendientes habían seleccionado veinte

9 Adkins (1972) 13; (1997) 697. MacIntyre (1966) 16, observa que con la denotación de agathós no sólo nos informamos de lo que es un hombre es, sino además de lo que podemos esperar de él. Así, se espera que la conducta del noble guerrero y justo gobernante sea permanente en el tiempo.

10 Lasso de la Vega (1963) 292.

11 Lledó (1988) 29.

12 Lledó (1988) 23-24. Ver también: Lasso de la Vega (1963) 292. 
guerreros para emboscar y asesinar a Telémaco (Od. 4.778). Esos veinte son referidos con el término áristoi. Se les encomienda la más vil de las tareas, pero si en ella son valientes y efectivos, entonces son los mejores y más aptos para realizarla; son, en consecuencia, áristoi.

En la Ilíada, Agamemnón no pierde su condición de agathós, sin importar cuan soberbio sea, cuan terco se mantenga en su obstinada idea de no devolver la esclava Briseida a Aquiles. Su fuerza y coraje lo ponen por encima de los juicios de sus súbditos. Mientras sea el más poderoso de los griegos, su estatus no se ve comprometido por sus actos. Además, al comenzar la guerra, Néstor recomienda a Agamemnón separar a los contingentes por lugar de origen, de manera que le sea posible determinar cuáles son buenos guerreros y cuáles kakós (Il. 2.362). Los kakós aparecen con poca frecuencia o, dicho de otro modo, Homero no desperdicia tiempo en su relato refiriéndose a los inservibles y bajos de la sociedad ${ }^{13}$. Este término se utiliza en dos sentidos, tanto para denotar a aquel carente de estatus social, ya sea el siervo o el pobre (Od. 15.324), como para aquel que muestra debilidad o cobardía en la batalla (Il. 2.360 ss.). El claro ejemplo de un kakós es Tersites. En el canto segundo de la Ilíada, intenta persuadir a los aqueos de abandonar a Agamemnón por ofender a Aquiles y retornar a Grecia (Il. 2.212 ss.). Allí Tersites señala que Aquiles es superior a Agamemnón, juicio que, como veremos más adelante, no todos los dioses comparten. Incluso Tersites, el más bajo de los mortales, descrito por Homero como patizambo y cojo, de hombros encorvados y cabeza picuda, es capaz de distinguir la condición de agathós de un hombre. Incluso el más torpe y feo reconoce la grandeza cuando la tiene a la vista ${ }^{14}$. Fuera de su carácter anecdótico, Adkins encuentra en este pasaje una razón más para afirmar la aceptación generalizada de los valores sostenidos por la sociedad homérica, tanto por nobles como plebeyos.

Las excelencias aquí descritas, que el hombre homérico valora más que a ningunas otras, son generalmente agrupadas bajo el término areté. Esa areté hace referencia, entonces, a una cualidad interna que denota la excelencia y eficacia de un hombre valiente y noble. Se contrapone, de esa forma, a otro concepto, la timé, que se caracteriza por denotar cualidades que, aunque le pertenecen, son externas al hombre. Revisemos, entonces, este concepto y el sentido que puede dársele en el contexto de la épica homérica.

13 Adkins (1972) 13.

14 Adkins (1972) 13-14. 


\section{La dimensión material y la timé}

Además de los mencionados hasta aquí, existe otro término de mucha relevancia al momento de considerar los aspectos morales del mundo de Homero: la timé. Este concepto expresa fundamentalmente, entre sus diversos rangos de significación, las posesiones por las que el agathós se destaca por encima de otros ${ }^{15}$. Con anterioridad hemos mencionado que la función principal del agathós es la de defender y engrandecer a su oikos. De acuerdo al uso que se le da en el poema, la timé hace referencia, fundamentalmente, a los medios materiales con los cuales cuenta el agathós para llevar a cabo dicha tarea ${ }^{16}$. Este tópico, según Adkins, es capaz de servir de clave interpretativa para la generalidad de la conducta humana en ambos poemas. La principal motivación y preocupación del hombre homérico es la de defender su timé y, si es posible, adquirir más ${ }^{17}$.

En este sentido, Adkins no está alejado de la realidad presentada en los poemas. La trama entera de la Ilíada se desenvuelve a través de constantes movimientos del concepto de timé. El primer gran argumento es el inicio de la guerra producto del rapto de Helena por parte de Paris (Il. 1.150 ss.) y el consecuente menoscabo de la timé de Menelao. El segundo se produce por la disputa entre Agamemnón y Aquiles por la posesión de Briseida (Il. 1.180 ss.), que termina en una ofensa y una disminución de la timé del hijo de Peleo. En tercer lugar está el asesinato de Patroclo por parte de Héctor en el canto 16. Patroclo reviste, bajo la forma de un phílos, parte de los elementos con los que cuenta Aquiles para defender su oíkos ${ }^{18}$, lo que significa que su asesinato constituye una gran ofensa y disminución por parte de un tercero de su timé. Este evento desata la famosa ira de Aquiles que es la trama central del poema.

Entre los medios con los que cuenta un agathós para defender su oíkos, y que constituyen su timé, se cuentan tierras, armas y herramientas, además de las personas: esposa, hijos y aliados (phílos). Esto demuestra, según Adkins, que los seres humanos no tienen, en el pensamiento homérico, derechos en tanto humanos, "ellos sólo poseen aquello que, en el caso del agathós, pueden defender por sí mismos; y en el caso de los

\footnotetext{
15 Adkins (1972) 14-15.

16 Adkins (1997) 705.

17 Adkins (1972) 15.

18 Adkins (1972) 16.
} 
demás, lo que les puede ser garantizado por un individuo más poderoso, con quien están unidos ya sea por nacimiento, dependencia económica directa, matrimonio u otra causa"19.

Claros ejemplos de la dimensión material de la timé pueden ser encontrados en los poemas. En el canto nueve de la Ilíada, Fénix aconseja a Aquiles aceptar los regalos (timé) que se le han ofrecido a cambio de la timé perdida a causa de Agamemnón (Il. 9.600). En el canto doce del mismo poema Sarpedón y Glauco reciben timé por parte de sus pares (asientos de honor en los banquetes y más comida) por su aporte, en timé, a la comunidad de aqueos (Il. 12.310). En el caso de la Odisea, Adkins repara en el hecho de que el delito de los pretendientes no es buscar unirse a Penélope mientras su esposo estaba vivo, sino que, en la larga espera, consumían los bienes, la timé de Odiseo (Od. 20) ${ }^{20}$.

Ante la inminencia de la pérdida de timé por parte de un tercero, el agathós homérico debe reaccionar. Esto significa una amenaza con alejarlo de los dioses (cuya timé es la más elevada de todas) y acercarlo al peldaño más bajo de la escala, a saber, el mendigo vagabundo (Il. 9.648) carente de los medios necesarios incluso para asegurar su propia existencia ${ }^{21}$.

Resulta evidente, entonces, que en la Grecia descrita por Homero la consideración de lo que más tarde llamaremos 'honor', queda relegado de las altas reflexiones morales y es reducido a una cuestión de carácter material, práctica y con un claro sentido social. En palabras de Adkins "la timé en Homero hunde sus raíces en lo material, y resulta esencial para la existencia del héroe" ${ }^{\prime 2}$. De esa forma, la aspiración del agathós, antes que una tranquila conciencia o una perfección de su humanidad, consiste básicamente en la obtención, defensa y disfrute de su timé23.

19 Adkins (1972) 16.

20 Adkins (1997) 703-4. Ver también: MacIntyre (1966) 17.

21 Adkins (1997) 708.

22 Adkins (1997) 702.

23 Lasso de la Vega (1963) 294. 


\section{Los dioses}

Si dirigimos nuestra mirada hacia los dioses en busca de juicios morales objetivos y ajustados a parámetros racionales, nos veremos grandemente decepcionados. Los valores morales de los dioses homéricos no difieren de aquellos de los hombres ${ }^{24}$. La única distinción es que, en palabras de Fénix, cuando se trata de los dioses "su areté, timé y fuerza son mayores" (Il. 9.497).

La timé, por ejemplo, funciona para los dioses de manera muy similar a la de los humanos: "ellos demandan timé de los hombres bajo la forma de sacrificios, ofrendas y templos; y son los resultados, no las intenciones, los que tienen validez: olvidar un sacrificio es tan despreciable como voluntariamente rehusarse a hacer uno"25. Para los dioses un aspecto crucial es esta rendición de honores. El hecho de que un hombre actúe de manera injusta con aquellos que lo rodean no es de incumbencia para ellos. Es la mismísima Atenas quien defiende este punto ante Zeus intentando persuadirlo de que le preste ayuda al errante Odiseo (Od. 1.60 ss.). De la misma forma, cuando Eneo omite a Artemis en las hecatombes que había ofrecido a todos los dioses, no hay una distinción clara en la voluntariedad de ese acto y, sin embargo, es castigado por la divinidad (Il. 9.536) ${ }^{26}$.

De la misma forma, y como es sabido, Zeus es el protector de los suplicantes, invitados y viajeros. Dado que todos aquellos requieren protección, sería aischrón para un agathós (siendo Zeus el agathós por excelencia) no prestarles ayuda o defenderlos ante otros. Esto genera un lazo de amistad entre Zeus y el mortal agathós protector. El suplicante protegido por el agathós forma parte de la timé del dios (de la misma forma que Patroclo forma parte de la timé de Aquiles), y cuando el agathós protege al allegado, lo que hace es proteger la timé de Zeus, transformándose así en aliado (phílos) del dios. Por ello es que no acoger al viajero es una gran ofensa a Zeus, es menoscabar su timé. Si Menelao invadió Troya por un detrimento a su timé, cuanto más habrá que temer a Zeus en su ira.

A partir de esto, es posible inferir que los dioses tenían motivaciones similares a las de los hombres para actuar y para enjuiciar moralmente de la manera en que lo hacían. Más allá de si esta deducción es precisa a la luz

24 Lasso de la Vega (1963) 296.

25 Adkins (1972) 19.

26 Lasso de la Vega (1963) 296-7. 
de los textos y evidencia que poseemos, todo parece indicar que los griegos tenían una intuición de este tipo.

Por otra parte, la timé adquirida que deriva de una relación de amistad con un dios es menor que aquella que deriva de un lazo sanguíneo con una divinidad, tal como lo atestigua el mismo Zeus al comparar a Aquiles y Héctor en el canto 24 de la Ilíada (Il. 24.55 ss.). Héctor, un hombre piadoso que honra a los dioses, posee menos timé que Aquiles, hijo de una divinidad. El actuar de los dioses no difiere cualitativamente de las consideraciones morales de los hombres. Polifemo falló terriblemente en su labor de anfitrión para con Odioseo y sus acompañantes, pero "él era hijo de Poseidón: le bastaba con rezar a su padre para que éste persiguiera a Odiseo, independiente de si era justo o no" ${ }^{27}$. De la misma forma, no fue porque la postura de Aquiles fuera la justa que Zeus se encargó de que los griegos tuvieran malos resultados en batalla mientras Agamemnón no retribuyera a Aquiles su timé: esto sucedió porque Zeus debía el favor a la madre de Aquiles. Fue la relación de sangre entre Tetis y Aquiles la que permitió este favor de Zeus ${ }^{28}$.

Resulta claro que las divinidades de la sociedad homérica no garantizan objetividad y racionalidad. Sus parámetros morales son los mismos que aquellos de los mortales, con la diferencia que ellos los ejercen desde una posición de superioridad. Esa superioridad, de acuerdo a las palabras Fénix, no les viene dado por una sabiduría o un conocimiento universal de las formas morales, sino simplemente porque son más poderosos que los hombres. Es el poder quien les otorga la capacidad de juzgar y encarnar el ideal de la moralidad para el hombre homérico. Es más, hay incluso algunos autores que sostienen que los hombres lo que hacen no es más que someterse irremediablemente a los dictámenes tiranos de las divinidades. Así entendido, los actos de los hombres no le son imputables en tanto son reflejo de la desesperación humana por agradar a los dioses, y sus repercusiones deben explicarse bajo ese prisma y no como decisiones voluntarias y libres ${ }^{29}$.

27 Adkins (1997) 709.

28 Adkins (1997) 709.

29 Para esta interpretación ver: Mas (2003) 39-46. 


\section{Conclusión}

En general, los motivos de acción de la Ilíada y la Odisea son los de un agathós contra otro agathós. Ya sea Aquiles contra Agamemnón o Héctor, u Odiseo contra los pretendientes. Es en esta interacción que se evidencia el uso de los conceptos morales del mundo arcaico. En palabras de Adkins: "los valores más enfáticos alaban el éxito y condenan el fracaso cuando se trata de asegurar la prosperidad y estabilidad del oikos; y tan pronto como el agathós se siente amenazado, siente que puede perder timé, todas las demandas del grupo de valores son actualizadas: él debe asegurar el éxito de su oíkos y debe prevenir, para el oíkos o para él, el perder terreno en comparación con otro oíkos o agathós, a través de medios efectivos, sean justos o no". ${ }^{30}$ Esto ya evidencia una idea central que hemos intentado esclarecer a lo largo de este artículo, a saber, los valores del hombre homérico no obedecen a conductas deseables y acordes a una cierta naturaleza humana (como será el caso de las éticas de la virtud de la filosofía clásica griega), sino que, más bien, esos valores responden a determinadas condiciones contextuales y, especialmente, condiciones sociales. ${ }^{31}$ Lledó sostiene que "este sistema de valores emana, directamente, de la narración épica [...]. No hay, que sepamos, ninguna reflexión paralela a la que ya se hubiesen planteado las razones que sustentan la coherencia o el sentido del comportamiento". ${ }^{32}$ No hay una filosofía de fondo contra la cual se contrasten las obras de los mortales. No hay un sistema de valores fundados en las reflexiones de unos pocos filósofos iluminados. El mundo del Homero responde, en términos morales, a las necesidades que le impone su contexto; es la supervivencia la que marca el camino de su acción. Es la utilidad de los actos en tanto favorecedores de la convivencia entre los hombres lo que les otorga su valor y es, en base a ella, que adquieren o pierden su provecho. ${ }^{33}$ Así, es posible afirmar que no encontramos en los poemas homéricos una 'teoría ética', una reflexión sistemática y fundamentada que justifique los actos humanos, sino más bien, en palabras de Aristóteles, una enérgeia (Nic. Eth. 1.8.1098b 33), un

30 Adkins (1972) 21.

31 Lasso de la Vega (1963) 292-294.

32 Lledó (1988) 16.

33 Lledó (1988) 16. 
obrar que determina nuestro ser. ${ }^{34}$

Adkins observa, además, que el esquema de valores que se evidencia en la conducta de los hombres homéricos, no obedeciendo a normas predicadas luego de un riguroso análisis intelectual, es contradictorio en sí mismo. En dos ocasiones los héroes, siguiendo estrictamente el código del agathós, no cumplen su objetivo, sino que causan un daño mayor. En la Ilíada, Aquiles señala a los embajadores enviados por Agamemnón para aplacar su ira, que no hay timé que repare el daño que se le ha hecho (Il 9.308 ss.), lo que resulta en la muerte de una gran cantidad de griegos. Odiseo sostiene lo mismo: no hay cantidad de timé que repare el daño que se le ha causado (Od. 22.45 ss.), conduciéndolo a asesinar a más de un centenar de pretendientes, disminuyendo la habilidad de Ítaca de defenderse a sí misma. De esa forma, los juicios morales homéricos no son consistentes y las metas que se fija no son, a fin de cuentas, coherentes con los valores que profesa.

¿De dónde, cabe preguntarse, nace esta contradicción? Como mencionamos, las evaluaciones y conceptos morales en Homero no escapan del ámbito práctico. Los valores no son nociones universales y abstractas que valgan por sí mismas. Ellos dependen estrictamente de la práctica, del contexto social en los que se desarrollen. En ese sentido resulta imposible esperar de un esquema subjetivo y, por así decirlo, utilitarista, que se comporte de manera coherente y sostenida en el tiempo. Los conceptos morales son, en este sentido, esclavos del quehacer humano y de las consideraciones de lo que la sociedad juzgue como útil o pertinente para su conservación y longevidad.

¿Qué sentido tiene, entonces, estudiar un esquema moral vacío de contenido y sujeto a parámetros subjetivos? Adkins analiza esta pregunta a la luz de la introducción de Alfred Ayer de las ideas del Círculo de Viena en el mundo angloparlante y resalta el hecho que cuando acudimos a Homero, no debemos, precisamente, buscar objetividad y reflexión filosófica. ${ }^{35}$ El mundo homérico es un mundo imbuido en la praxis, todavía lejos de la filosofía ateniense y marcado por las durezas de la sobrevivencia y la convivencia de los estados. Es por eso que, como se mencionó en el

34 Este concepto configura una especie de estado prefilosófico, donde es la acción la que fundamenta las consideraciones morales. Para esta idea ver: Lledó (1988) 16.

35 Adkins (1997) 695-97

172 
comienzo, la mirada que dirigimos al mundo descrito por el poeta debe ser contextualizada, con el objetivo de entender las raíces de un esquema moral que marcó la historia de Grecia, sin importar si éste resulta coherente u objetivo. El análisis desarrollado por Adkins no está, sin embargo, exento de dificultades y problemáticas en su planteamiento. El destacado clasicista Anthony Long dedica un artículo completo a hacer un exhaustivo escrutinio a dichas problemáticas. ${ }^{36}$ En este artículo hemos abordado las temáticas generales propuestas por Adkins, intentando no hacer un compromiso definitivo con los aspectos que ofrecen duda o cuestionamientos, pues ello nos llevaría a un estudio demasiado extenso y que merece una exposición por sí misma.

En un trabajo posterior sería interesante revisar el desarrollo que tuvieron los presupuestos morales presentes en Homero, para así desentrañar la influencia que pueden haber tenido en las reflexiones éticas posteriores. Algunos autores han afirmado que ya entre la Ilíada y la Odisea se puede observar el paso de una ética marcadamente bélica a una ética ajustada a tiempos de paz. ${ }^{37}$ Otros sostienen que los usos de los términos agathós y kakós adquirieron otro significado en la época posthomérica, señalando un cambio en su uso y significancia. ${ }^{38}$ Así, un estudio de la influencia de las concepciones morales arcaicas en períodos posteriores podría enriquecer nuestra comprensión de ellos y la variedad del campo semántico que presentaron en diferentes períodos de la Grecia antigua.

\section{Bibliografía}

ADKINS, A.W. H. (1971) Homeric Values and Homeric Society. Journal of Hellenic Studies. Vol. 91. pp 1-14

(1972) Moral Values and Political Behaviour in Ancient Greece. Londres: Chatto \& Windus.

(1997) "Homeric Ethics". En Morris, I. y Powell, B. (Eds.) A New Companion to Homer. Londres: Brill.

36 Ver: Long (1970) 121-139. Adkins, de hecho, escribió un artículo para contestar a las críticas de Long: ver Adkins (1971) 1-14.

37 Lasso de la Vega (1963) 295-316 sostiene esta idea y en el desarrollo de su artículo entrega diversas ideas que permiten al lector advertir las diferencias entre los códigos de uno y otro poema.

38 Para este abordaje ver: MacIntyre (1966) 18-19. 
MATÍAS LEIVA R.: Ética y sociedad. A. W. H. Adkins y los valores morales en...

ARISTÓTELES (1985) Ética Nicomaquea. Madrid: Gredos.

HOMERO (1996) La Ilíada. Madrid: Gredos.

(1993) La Odisea. Madrid: Gredos.

LASSO DE LA VEGA, J. (1963) “Ética Homérica”. En Gil, L. (Ed.), Introducción a Homero. pp 289-308. Madrid: Ediciones Guadarrama.

LLEDÓ, E. (1988) "El mundo homérico". En Camps, V. (Ed.). Historia de la Ética. 1. De los griegos al Renacimiento. pp 15-34. Barcelona: Crítica.

LONG, A. (1970) Moral and values in Homer. Journal of Hellenic Studies. Vol. 90. pp 121-139.

MACINTYRE, A. (1966) Historia de la Ética. Barcelona: Paidós.

MAS, S. (2003) Ethos y Polis. Una historia de la filosofia práctica en la Grecia clásica. Madrid: Istmo. 